\title{
Challenges and Some Recommendations Related to Estimation of in-situ Swelling Pressure of Gouge Materials
}

\author{
Bjørn Nilsen ${ }^{1}$ (1)
}

Received: 1 December 2020 / Accepted: 17 June 2021 / Published online: 2 July 2021

(c) The Author(s) 2021

\begin{abstract}
Faults/weakness zones with gouge containing swelling clay (smectite) have in several cases caused serious stability problems in tunnels. The first part of this paper describes briefly some recent cases of instability/cave-in where swelling clay has been a main cause of the incident, followed by brief reviews of structure and properties of smectite and relevant laboratory test procedures. Main focus is placed on swelling pressure, which is a key parameter for understanding the potential problems that may develop when crossing a major fault/weakness zone, and a key factor also for analysis of stability and rock support requirement. Laboratory test results presented in this paper illustrate that swelling pressure may vary considerably between different locations of the same zone, and that test results based on standard laboratory preparation do not correspond well with results based on testing of in situ undisturbed samples. Swelling pressure based on laboratory testing, therefore, should not be used directly in stability analysis and rock support design. Recommendations on proper use of laboratory test data are given at the end of the paper.
\end{abstract}

Keywords Swelling $\cdot$ Smectite $\cdot$ Fault $\cdot$ Weakness zone $\cdot$ Swelling pressure $\cdot$ Instability

\section{Introduction}

Tunnel instability related to swelling clay gouge in faults/ weakness zones may have very serious consequences and should by all means be prevented. Although many believed such incidents mainly to belong to the past, several recent cases clearly illustrate that this issue definitely should be taken seriously also today. A review of 65 international cases of cave-in, mainly from the last 20 years, was published by CEDD (2015), and Brox (2019) has published a review of several recent cases related to hydropower projects. In many of the cases described in those reviews, swelling has been the main, or at least a contributory cause of the incident.

From recent Norwegian tunneling, which this paper is mainly focusing on, the incidents at the Hanekleiv highway tunnel (2006), the Atlantic Ocean subsea road tunnel (2008), the Nedre Vinstra hydropower project (2015) and Matre hydropower project (2017) are particularly worth mentioning. Swelling clay in faults/weakness zones crossing these

Bjørn Nilsen

bjorn.nilsen@ntnu.no

1 Norwegian University of Science and Technology, Trondheim, Norway tunnels was found to be a main cause of the incidents, which fortunately did not cost lives, but caused large economic loss. The incidents at the road tunnels were taken very seriously by the road authorities and caused new, stricter guidelines and requirements to be implemented. The incidents at the hydropower projects caused large economic loss due to required repair work and lost power production (estimated to 40 mill. NOK for Matre). For further details regarding these Norwegian incidents, reference is made to Nilsen (2011, 2016, 2018).

Instability may occur at any time during construction and operation of a tunnel. In some cases, cave-in takes place at the face during excavation, (as for the Atlantic Ocean tunnel), while in other cases instability develops slowly with cave-in long time after completion of the tunnel (like for the Hanekleiv tunnel, about 10 years after completion, and the Matre tunnel, about 1 year after completion). The situations after cave-in at these tunnels are illustrated in Fig. 1.

The cases in Fig. 1 are all connected to faults/weakness zones in crystalline hard rock; Cambro-Silurian syenite at the Hanekleiv tunnel and Precambrian gneiss at the Atlantic Ocean and Matre tunnels, respectively. Based on site inspections by the author short time after the incidents, the 

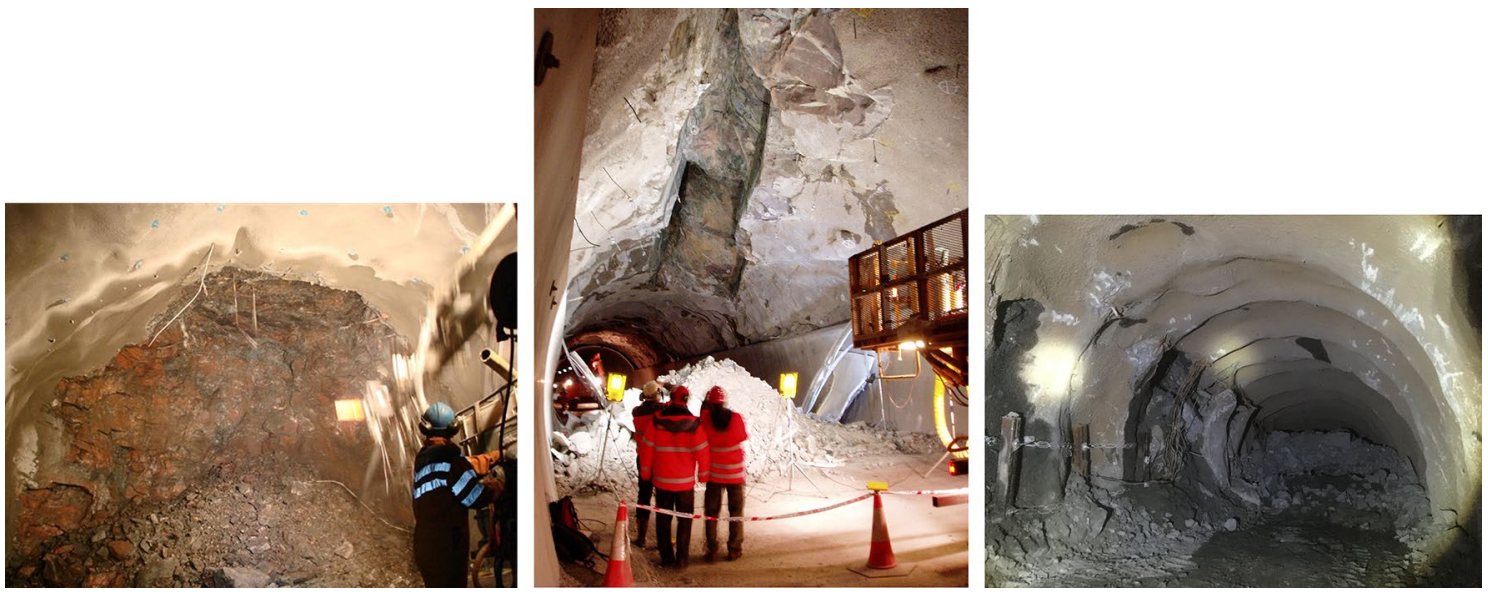

Fig. 1 Examples of recent cases of instability; Atlantic Ocean tunnel (left), Hanekleiv (middle) and Matre (right)

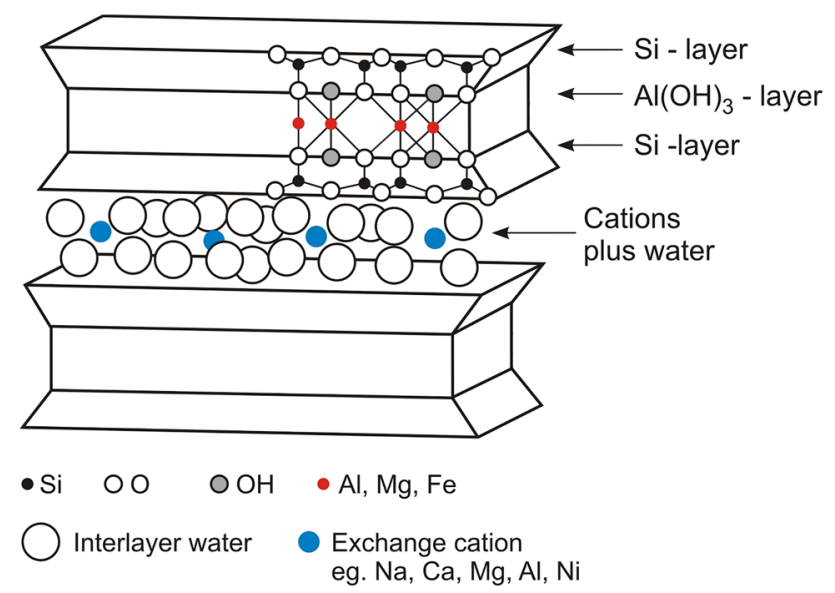

Fig. 2 Basic structure of montmorillonite, with each main unit consisting of two Si-layers (tetrahedral layers) and one $\mathrm{Al}\left(\mathrm{OH}_{3}\right)$-layer (octahedral layer)

Q-values (NGI 2015) for all these cases were estimated to around 0.01 (i.e. "extremely poor" to "exceptionally poor").

If instability occurs, the rock support obviously has been insufficient. In cases with faults/weakness zones this is normally related to poor understanding of the situation in the tunnel, insufficient sampling, inadequate data from laboratory testing and/or underestimation of the effects of swelling on rock support structures. The main objective of this paper is to discuss the challenges related to quantification of swelling pressure for use in stability analysis and rock support design.

\section{Structure and Properties of Swelling Clay}

The character of gouge material; i.e. the loose material in faults/weakness zones, may vary within wide limits. Most commonly, the gouge material consists of a mixture of coarse rock fragments and finer particles, including clay. Minerals with very low internal friction (graphite, talc, clay minerals, chlorite etc.) and, particularly, those with swelling capability ("swelling clay"), cause the largest stability problems in tunneling, and will be discussed in the following.

Swelling clay, or smectite, belongs to the mineral group phyllo-silicates, characterized by a sheet-like structure as illustrated in Fig. 2. The most active smectite-mineral is montmorillonite, which has a structure with two siliconlayers ("tetrahedral layers") and one $\mathrm{Al}\left(\mathrm{OH}_{3}\right)$-layer ("octahedral layer") as shown in the figure. One montmorillonite grain, or particle, consists of many such units stacked on top of each other, with relatively weak bonding between the unit layers. The grain size is very small (typically in the order of magnitude of $10^{-6} \mathrm{~mm}$ ).

Montmorillonite is formed by hydrolysis of feldspar or by hydrothermal processes in rock fractures/discontinuities. The mineral may be recognized in-situ based on its very slippery character and identified in laboratory by mineralogical analyses (XRD and DTA). Due to the weak bonding between the main units, water molecules and cations such as $\mathrm{Ca}^{2+}, \mathrm{Mg}^{2+}, \mathrm{Na}^{+}$and $\mathrm{K}^{+}$may enter the space between the unit layers (so-called lattice expansion).

A special feature of montmorillonite is that some of the $\mathrm{Si}$ - and $\mathrm{Al}$-atoms of the tetrahedral and octahedral-layers are substituted by atoms with lower valence $\left(\mathrm{Si}^{4+}\right.$ often substituted by $\mathrm{Al}^{3+}$ and $\mathrm{Al}^{3+}$ often substituted by $\mathrm{Mg}^{2+}$ ). As result, the surface charge will be negative. This is compensated by positively charged ions being attracted and bonded to the surface of the clay particle. The swelling process has two stages. Step 1 is 
hydration, represented by adsorption of water molecules to the negatively charged mineral particle due to their dipole feature. Step 2 is osmotic swelling, caused by the higher concentration of cations in the water between main units than outside and water flowing towards the highest concentration to establish equilibrium.

The in-situ swelling potential of smectite/montmorillonite depends on two factors:

1. The internal conditions, or the potential swelling capacity, defined mainly by type and amount of smectite and exchangeable cations.

2. The external conditions, determining whether the potential swelling capacity may be mobilized or not. The most important factors here are degree of compaction and option for water access.

For identical external conditions, swelling clay with the highest potential swelling capacity will give the highest swelling pressure also in-situ. If the external conditions are different, it may, however, well be the case that swelling clay with the lowest potential swelling capacity will give the highest in-situ swelling pressure.

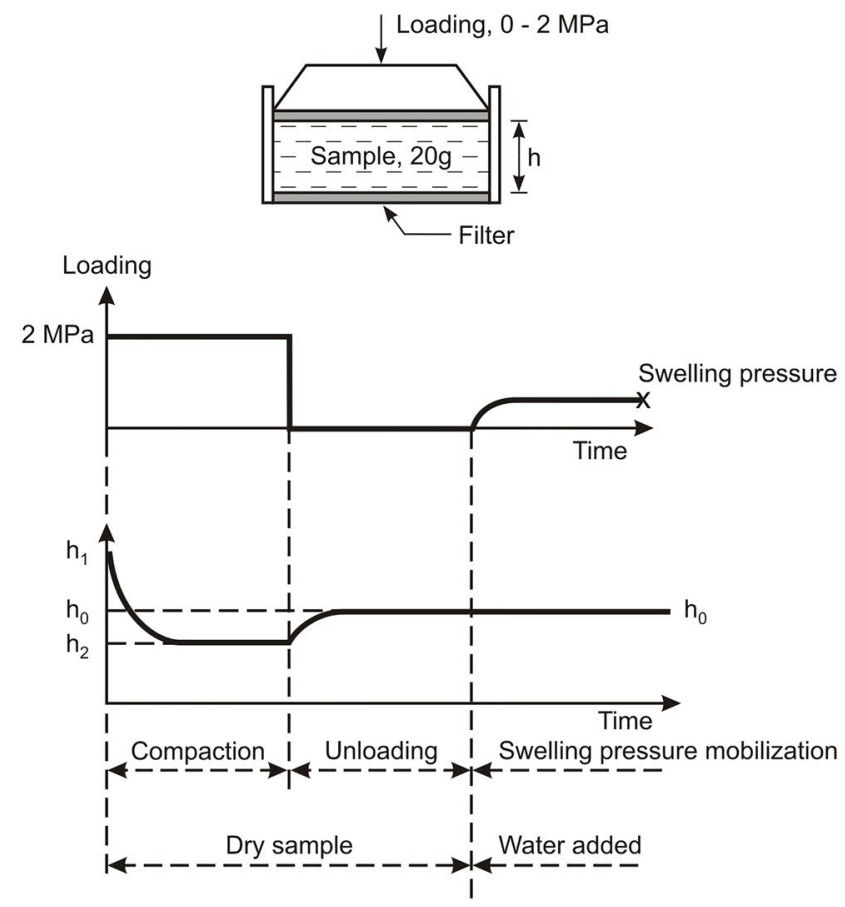

\section{Laboratory Test Procedures}

The laboratory test methods used at NTNU for swelling clay are the free swell test and testing of swelling pressure at constant volume. The latter is similar to the ISRM suggested method for laboratory testing of swelling rocks (ISRM 1999), which is, however, based on using powder sample of crushed rock, while the NTNU-method uses precipitated gouge material $<20 \mu \mathrm{m}$. In standard NTNU-analysis, the samples obtained by settling are further prepared by drying at $105^{\circ} \mathrm{C}$ and careful grinding in porcelain mill before being tested.

The free swell test is a simple index test, based on letting $10 \mathrm{ml}$ of sample material swell freely after sedimentation in water. It can be used for an estimate of potential swelling capacity, but not for estimation of support requirement. For that purpose, only the swelling pressure test, shown in Fig. 3, is applicable. The sample, consisting of $20 \mathrm{~g}$ dry material prepared as described above, is placed in an oedometer cell and compacted by applying a loading of $2 \mathrm{MPa}$ till deformation has ceased (at sample height $h_{2}$ ). The sample is then unloaded and, when the height has reached a constant value $\left(h_{0}\right)$, the volume is kept constant during the remaining part of the test and the sample given free access to water, causing swelling pressure to be mobilized. The test is run until swelling pressure has stabilized, which normally takes around $24 \mathrm{~h}$. The loading required

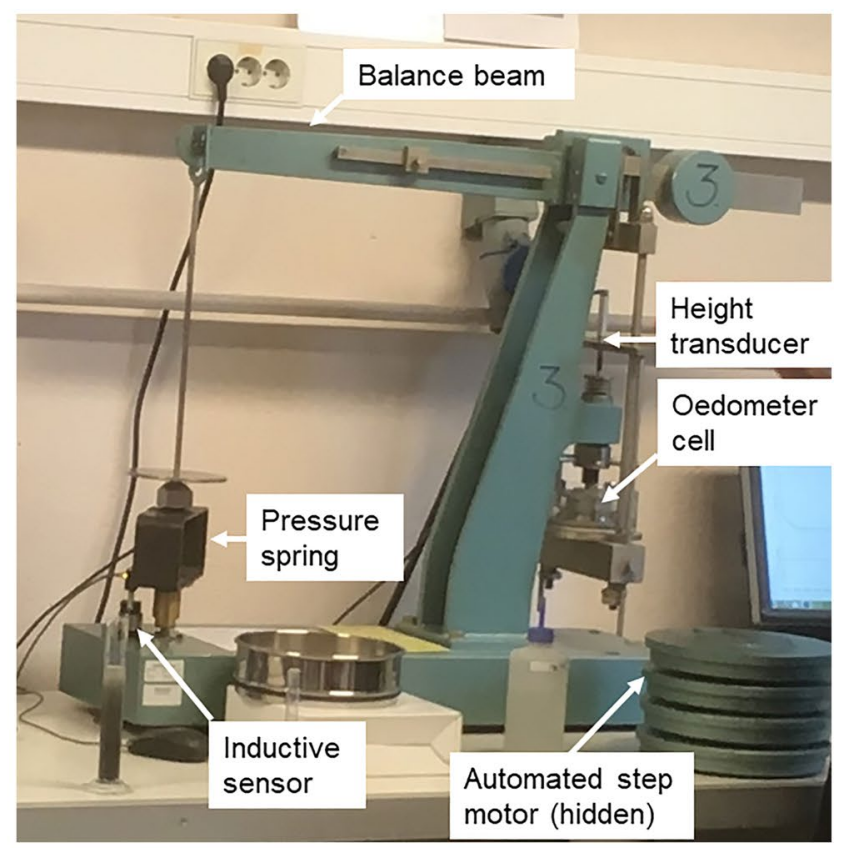

Fig. 3 Principle for testing swelling pressure at constant volume (left) and photo showing one of the oedometers used at the NTNU-laboratory (right) 
to keep the sample height constant at the end of the test is defined as swelling pressure at constant volume (Nilsen and Palmstrøm 2000). High swelling pressure according to NTNU-classification is $>0.3 \mathrm{MPa}$. For extreme cases swelling pressures of $>2 \mathrm{MPa}$ have been measured based on this method.

At the NTNU-laboratory, more than 500 gouge samples have been tested based on the methods described above (Mao et al. 2011a; Dahl et al. 2013). The large database of swelling pressures measured for cases where at the same time information of stability and applied support in the tunnel has been available, is of great value as part of the basis for designing rock support in future tunnels.

The procedures for preparation of samples for swelling tests (settling, drying, grinding) cause considerable damage to the in-situ structure of the swelling clay. As described above, the preparation procedure for the NTNU-test is not quite according to the ISRM suggested method, and sample preparation procedures differing from the ISRM suggestion are used also at other laboratories (Piaggio 2015; Selen et al. 2018). Swelling pressures measured at different laboratories therefore will not be comparable, and laboratory testing in general cannot provide results that can be used directly in support design.

In any case, laboratory measurement of swelling pressure gives only a measure of potential swelling capacity. To be able to evaluate or analyze stability and rock support requirement, the in-situ conditions (external conditions) also need to be taken into consideration.

\section{The Challenges Regarding Representativeness and Preparation of Samples}

When encountering a fault/weakness zone the geological conditions at the face may vary considerably. The swelling pressure measured in laboratory therefore greatly depends on sample location. Also, it may be questioned whether only one sample is sufficient, and how many should alternatively be taken.

Some examples of variations of swelling pressure within one single blast round in weakness zones are shown in Fig. 4. The examples include two of the cases shown in Fig. 1 (Matre and Hanekleiv, labeled M and H, respectively), and the following three cases investigated as part of NTNU MSc-assignments (Hetlebakke 1991; Tyssekvam 1996):

- Tevla, hydropower headrace tunnel in Cambro-Silurian metasandstone; labeled T1 and T2 (two different weakness zones).

- Romeriksporten, railway tunnel in Precambrian granitic gneiss, labeled R1a, R1b, R2a and R2b (two different weakness zones, each with two different sample locations).

- Bekkelagshøgda, railway tunnel in Precambrian granitic gneiss, labeled B.

For cases with two samples in Fig. 4, these are typically taken at the tunnel face near each wall, and for cases with three samples one additional sample is taken from the central part of the face. As can be seen, the values within one single location vary considerably, with the highest value between 1.2 and 9.1 times higher than the
Fig. 4 Swelling pressures measured for 2-3 samples collected at the tunnel face for nine different weakness zone locations at five different projects

\section{Variations in swelling pressure}

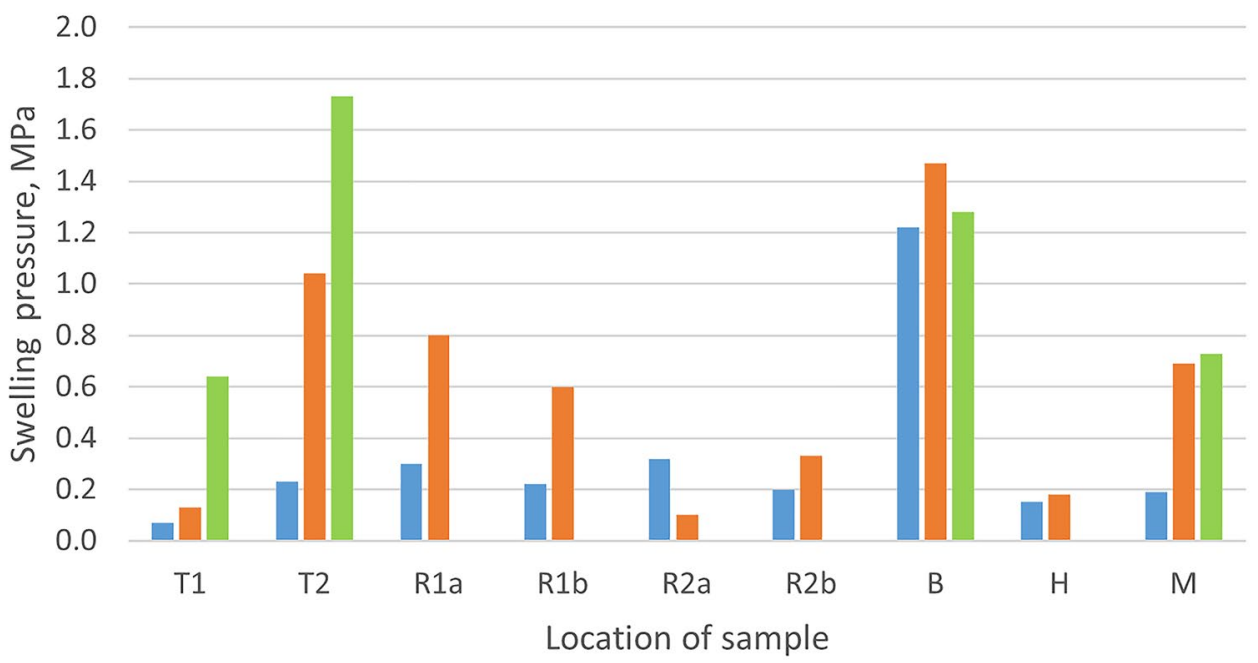


Fig. 5 Swelling pressures measured by traditional NTNU-laboratory testing (brown colored columns) versus testing based on in-situ "undisturbed" bulk material (black columns). Based on data from Tyssekvam (1996)

\section{Sample $<20$ m versus "undisturbed"}

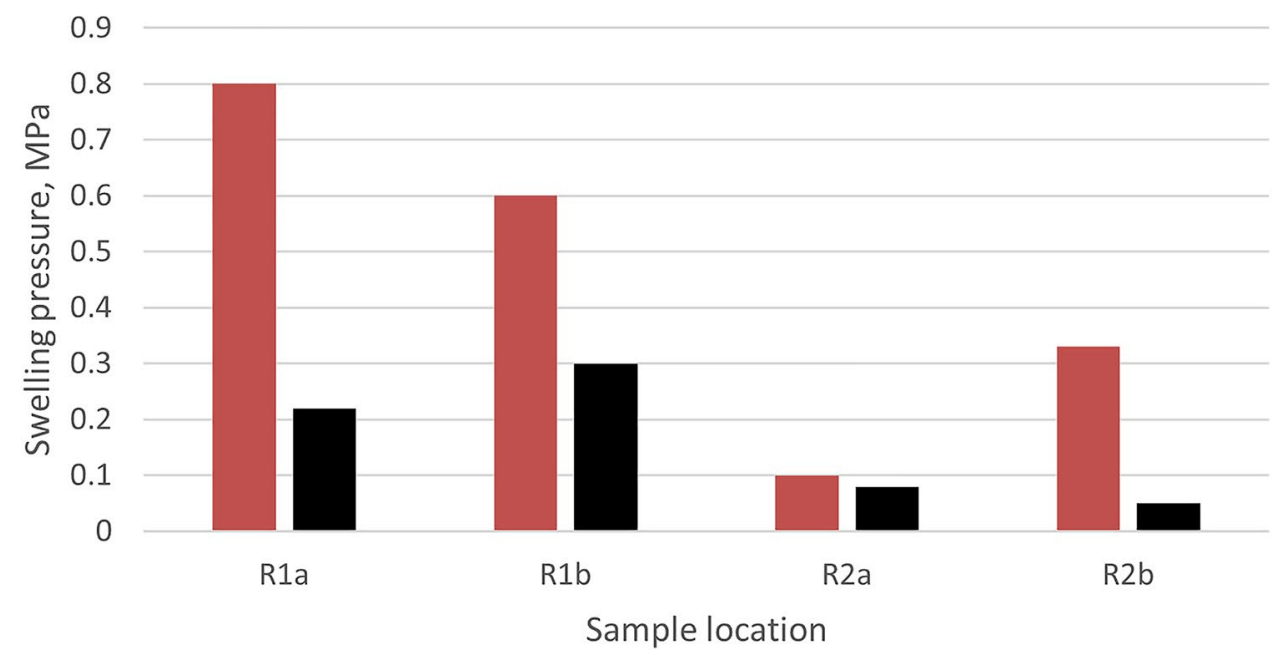

lowest. This illustrates that taking only one sample from a weakness zone, and assuming that the swelling pressure is evenly distributed in the zone, would be a gross oversimplification.

Since all samples have been collected in-situ from the wall or the face of the tunnel, and have not been stored or handled differently, the distinct heterogeneity of swelling pressures is believed definitely to be natural. The differences in swelling pressure within one group reflect the geological complexity for many tunnels in this type of geology, as illustrated particularly by the photo of the face of the Atlantic Ocean tunnel in Fig. 1 (left).

The procedures for handling and preparation of gouge samples, as described in Sect. 3, represent considerable disturbance of the in-situ structure. Swelling pressure measured in laboratory, regardless of test methodology, therefore will not be identical with in-situ swelling pressure. Normally, the swelling pressure in-situ will be considerably lower than what is measured in laboratory. This is mainly because the preparation process gives a higher concentration of smectite in laboratory samples, and because of the high degree of pre-compaction used in laboratory.

No examples of comparison between swelling pressure of gouge material measured in laboratory versus insitu are known from literature. At NTNU, comparison of laboratory results based on samples prepared according to the "traditional NTNU-method" with results based on samples representing in-situ "undisturbed" bulk material, was done in connection with a MSc-project (Tyssekvam 1996). For this, a specially designed measuring cell was used, allowing in-situ undisturbed samples of diameter up to $80 \mathrm{~mm}$ to be tested. Results from this testing, based on test material as for the R-series in Fig. 4, are shown in Fig. 5.
The results in Fig. 5 represent the R-samples in Fig. 4 shown in brown color. First, these samples were tested as in-situ "undisturbed" bulk material. Then, after preparation according to the traditional NTNU-procedure, the material $<20 \mu \mathrm{m}$ was tested as described in Sect. 3.

As can be seen from Fig. 5, the swelling pressures found by testing of in-situ material are generally lower, and mainly much lower, than the results based on testing of material $<20 \mu \mathrm{m}$. This is in line with what should be expected from the preparation procedure of the traditional test, where particles larger than $20 \mu \mathrm{m}$ are removed prior to testing. This gives an overrepresentation of material $<20 \mu \mathrm{m}$ compared to in-situ material. The findings in Fig. 5 also support results from tunnel monitoring, indicating that the loading of support structures is normally much lower than what would be expected from results from traditional swelling pressure testing (Grimstad et al. 2008; Mao et al. 2011b).

Undisturbed samples, therefore, will give swelling test results which are much better reflecting in-situ swelling potential than "disturbed samples", and whenever possible such samples should be used for testing. In practice this is seldom feasible for gouge materials of faults/weakness zones in hard rocks, since most such zones have a high content of coarse particles mixed up with the finegrained material. For any kind of sampling procedure, it is very difficult to have full control of deformation and potential change of gouge properties prior to sampling, and some degree of uncertainty, therefore, will always remain on the use of laboratory results as basis for support design. 


\section{Discussion and Conclusions}

To be able to evaluate the stability situation and design a proper rock support that will prevent instability to develop when crossing faults/weakness zones with swelling clay, the potential stability problem first of all needs to be identified and fully understood. Then, the input parameters for stability analysis need to be reliably quantified, and based on this rock support needs to be designed according to results from proper analysis/calculation. The most difficult part of this process is normally related to the quantification of input for design of rock (i.e. swelling pressure), which has been the main subject of this paper.

This study has clearly shown that there are many challenges and uncertainties related to sampling as well as laboratory testing of gouge material containing swelling clay, and laboratory results, therefore, should not be used directly in analysis/calculation.

Still, it is the author's experience that analysis of rock support requirement is in some cases based on only one sample taken from the tunnel face, and with swelling pressure measured for powder sample in laboratory as basis for support design. The results described above, as well as experience from other projects, show that such an approach may cause serious errors. To obtain more realistic and reliable input, the following measures are recommended:

- More than only one sample should be collected from each respective fault/weakness zone, and the samples should be from different locations, particularly in complex geological conditions where varying swelling pressure may cause uneven loading of support structures. At least three samples from different parts of the zone should be collected for testing in laboratory.

- The swelling pressure measured for powder samples in laboratory should not be used directly in stability analysis and rock support design. Based on investigations described in this paper and results from stress- and deformation monitoring of support structures in tunnels (i.e. Grimstad et al. 2008; Mao et al. 2011b), 50\% of the highest swelling pressure measured by standard laboratory testing is believed to be the maximum of what may be encountered in-situ. This perception has been incorporated in the tunnel guidelines published by the Norwegian public Roads Administration (NPRA 2020), indicating that the loading on tunnel rock support will be only around $30 \%$ of the laboratory measured swelling pressure.

In design calculation, the input parameters regarding swelling should reflect the variation reflected by laboratory testing; i.e. uneven loading on support structures should be taken into account whenever relevant. In cases where "undisturbed samples" can be collected (very rare for gouge materials, but more relevant for swelling rock such as some volcanic tuffs, shales and claystones), full control regarding air and liquid/moisture is of great significance as described by Ewy (2015). For disturbed samples, this is less important, since preparation of the sample in this case includes drying prior to testing.

In any case, due to the uncertainties related to estimation of swelling pressure at the design stage, close observation and control of the behavior or rock support is always recommended. If the behavior deviates from what was expected, reconsideration of the support design should be made based on monitored deformations and/or reconsidered swelling pressures.

Due to the disturbances caused by sampling and sample preparation, swelling pressure measured in laboratory can never accurately reflect in-situ swelling pressure in a tunnel. For improving future reliability of analysis of support structures affected by swelling pressure, it is considered particularly important to look further into relationships between laboratory values of swelling pressure and deformations of support elements measured in-situ, as described by Grimstad et al. (2008) and Mao et al. (2011a; b). Based on this, combined with numerical modeling, an empirical database making future estimation of in-situ swelling pressure more reliable, may be developed.

Funding Open access funding provided by NTNU Norwegian University of Science and Technology (incl St. Olavs Hospital - Trondheim University Hospital).

Open Access This article is licensed under a Creative Commons Attribution 4.0 International License, which permits use, sharing, adaptation, distribution and reproduction in any medium or format, as long as you give appropriate credit to the original author(s) and the source, provide a link to the Creative Commons licence, and indicate if changes were made. The images or other third party material in this article are included in the article's Creative Commons licence, unless indicated otherwise in a credit line to the material. If material is not included in the article's Creative Commons licence and your intended use is not permitted by statutory regulation or exceeds the permitted use, you will need to obtain permission directly from the copyright holder. To view a copy of this licence, visit http://creativecommons.org/licenses/by/4.0/.

\section{References}

Brox D (2019) Hydropower tunnel failures: Risks and causes. Proc. ITA-AITES World Tunnel Congress 2019, Naples, Italy 2019, CRC Press, pp 4386-4396

CEDD (2015) Catalogue of notable tunnel failures - case histories up to April 2015. Prepared by the Government of the Hong Kong Special Administration Region, Civil Engineering and Development Department, p.380 
Dahl F, Hagen S and Holmøy KH (2013) Development within determination of swelling properties-test apparatuses and methodology-swelling clays and rocks. Proc. Norwegian Annual Tunnelling Conf., NFF/NBG, Oslo, pp 19.1-19.17

Ewy RT (2015) Shale/claystone response to air and liquid exposure, and implications for handling, sampling and testing. Int J Rock Mech Min Sci 80:388-401

Grimstad E, Turnbridge L, Bhasin R, Aarseth A (2008) Measurement of forces in reinforced ribs of sprayed concrete. Proc. 5th Int. Symp. on Sprayed Concrete, Lillehammer, Norway

Hetlebakke JE (1991) Investigations of swelling clay from Meråker HPP. Norwegian Institute of Technology (NTH), MSc-project (in Norwegian)

ISRM (1999) Suggested methods for laboratory testing of swelling rocks. Int J Rock Mech Min Sci 36(3):291-306

Mao D, Nilsen B and Dahl (2011a) Laboratory testing of swelling gouge from weakness zone-principle and recent update. Proc. 45th US Rock Mechanics Symp., San Francisco, USA. ARMA $11-152$, p. 6

Mao D, Nilsen B, Lu M (2011b) Analysis of loading effects on reinforced shotcrete ribs caused by weakness zone containing swelling clay. Tunn Undergr Space Technol 26(2011):472-480

NGI (2015) Using the Q-system, rock mass classification and support design. NGI-handbook, p.56

Nilsen B (2011) Cases of instability caused by weakness zones in Norwegian tunnels. Bull Eng Geol Environ Springer 70:7-13

Nilsen B (2016) Reliability of swelling pressure testing for tunnel support evaluation. Proc. ITA-AITES World Tunnel Congress 2016, Dubrovnik, Croatia 2015, p.10
Nilsen B (2018) Cases of tunnel instability and cave in-lessons learnt and measures for prevention. Proc. ITA-AITES World Tunnel Congress 2018, Dubai, UAE 2018, p.10

Nilsen B, Palmstrøm A (2000) Engineering geology and rock engineering. Norwegian Group of Rock Mechanics (NBG), Handbook No. 2. Oslo, Norway

NPRA (2020) Guidelines for road tunnels. Norwegian Public Roads Administration (NPRA), Handbook V520, (in Norwegian), Oslo, p.139

Piaggio G (2015) Swelling rocks characterization: lessons from the Andean region. Proc. ITA-AITES World Tunnel Congress 2015, Dubrovnik, Croatia 2015, p. 10

Selen L, Panthi KK, Vergara MR (2018) Swelling pressures of some rocks using different test procedures. In: Proc. 2018 European Rock Mechanics Symp., St. Petersburg, Russia. Taylor \& Francis Group, pp 401-410

Tyssekvam I (1996) Weakness zones at Romeriksporten tunnel-Sampling and characterization of gouge material. Norwegian Institute of technology (NTH), MSc-thesis, (in Norwegian)

Publisher's Note Springer Nature remains neutral with regard to jurisdictional claims in published maps and institutional affiliations. 